\title{
Assessing the value of ILL to our users: a comparative study of three US libraries.
}

\section{Introduction}

"Thank you" are words heard by many Interlibrary Loan staff. These words help staff feel good about services and it indicates a library is providing a service desired by patrons.

"Thank you! That was fast" is an even better phrase for staff to hear. They now know speed might be an important factor for that patron.

"Instead of scheduling a weekend to drive to a library, one can access material at home, work, reread as often as needed, and at one's own pace. Having spent fortunes on research travel, ILL alters everything!!! Love it.”

This type of information received from a patron is even more valuable. It provides staff with positive feelings, but more importantly, demonstrates better the impact on the patron of the services provided.

Many interlibrary loan operations regularly receive complimentary comments like the first two noted above. It is important to note, though, that there is some question as to whether speed was important. In the second example, the patron just noted it was fast. With declining budgets and/or competing sources that need funds, it is vitally important that resource sharing operations gather better, more comprehensive data to understand the breadth of satisfaction and where patrons are dissatisfied. More importantly, interlibrary loan operations must also begin to understand the value placed on their services by their patrons. This information is vital to understand where to allocate resources, to satisfy patrons' needs, to support marketing and stakeholder support efforts, etc.

Leaders in the academic library community and beyond have started to call for libraries to wake up and introduce assessments that truly get at the value our patrons and partners place on what we do. David Schulenberger, at the ARL Assessment Conference in 2010, challenged libraries by stating that "Failure to use the data may be hazardous to your future" (Schulenberger 2010). Libraries can no longer talk within their walls about their contributions to their institutions and their communities. They must look outward and join the larger conversations, not only on their own campuses, but within their larger library communities and beyond.

The Association of College and Research Libraries also saw how important it is for libraries to align with institutional outcomes and to understand value. Megan Oakleaf's values work provides an extensive framework for understanding the why and starting to see the how 
(Oakleaf, 2010). A resource sharing operation that gathers extensive qualitative feedback like the third example above, not only understands the breadth of satisfaction, but also extensive awareness of how their services impact the patrons they serve. This information should drive workflow and policy decisions, inform stakeholders and more.

\section{Literature Review}

Inspired to focus on the value of Interlibrary Loan within the larger academic assessment movement, a framework from which to guide our study needed to be built. Looking at the literature, scholars contributing perspectives include Oakleaf (2010), Collette Mak (2011), and Jeanne Brown (2010), to name but a few. Resource sharing is identified as being within the library collection discussion of improving access and discoverability while shifting collections from print to digital as well as local institution ownership to consortium and collaborative collections.

Much assessment conversation and research about libraries focuses on the "value added" impact for successful students. Determining where the library contributes to that value for students and stakeholders is often seen as the key to our survival in the future. As each library determines how to navigate assessment within their own organization, we looked to studies and implementations including the "Value Indicator" (Brown, 2010) Through the use of surveys and follow up interactions with students, perception of the library's value can be managed in various ways: for example, the proportion of tuition fees spent on the library service, cost in relation to use, etc.

This idea of applying cost to value for patrons' perceptions of their libraries and library services is not a new trend in higher education assessment initiatives. Gaining insight into how students perceive the allocation of their tuition fees allows institutions to see where the gaps are in communicating to students the institution's goals for them as well as aligning those goals with student expectations. David Harless and Frank Allen performed this type of study in 1999; however, their study was focused on reference services in academic libraries. There has been little done in this area which specifically focuses on resource sharing and the value of this service to students and faculty within the context of their learning in academic institutions. (Harless 1999). We can see this type of research being done again and again. The issue with cost studies, however, is the lack of action that takes place after they have been completed - the failure to 
close the proverbial loop. As Oakleaf quotes frequently in her presentations, "Who cares?" This "who cares" factor must be considered in the assessment process or the pattern of collecting and evaluating data will continue with no true communications or benefits for the end users - the loop will remain open. Thus, "Many librarians have questioned the efficiency of reference desk service. During a time of strained resources for academic libraries, the question is legitimate” (Harless 1999).

Nothing has changed over a decade later. These studies are still being done, though the need to demonstrate value is the added layer that could encourage changes in behavior and spaces within the academic library.

Megan Oakleaf is a well-known name in higher education assessment circles. Her work lays out various methods including surveys and other established tools as well as organizational strategies to ensure "closing the loop" and following through on all stages of assessment. Her extensive report pulls together literature, trends, opportunities, definitions, etc. related to assessment in academic libraries, (Oakleaf, 2010). The one obvious perspective needed to implement effective assessment, is that of the patron. The patron is where the concepts of collection, methods, value calculations, etc. need to be centered. Is the patron receiving the benefits and understanding of provided services, utilizing the provided services, valuing them the way the library itself does? Are those provided services meeting the expectations of the patron as distinct from the library's expectations? How do we know the answers to these questions? What does the process look like in which these answers are gathered, analyzed, and communicated internally within the library as well as externally, back out to our patrons?

While much research has been published on academic libraries and assessment ideals with a broader scope, not much literature has been produced on specific services, especially resource sharing. Collette Mak (2011), Dennis Massey (2012), and others have produced works looking at the changing trends and growth of resource sharing over the past decades. One form of assessment can be used to change the backend workflow, or process, of resource sharing. More and more we are seeing these changes in workflow incorporating collection development initiatives such as patron driven acquisitions. Resource sharing data has also contributed insight into collection management practices, such as identifying subject areas most borrowed through interlibrary loan, which indicate the need to develop those local collections. Combining patron driven acquisitions into the resource sharing workflow is layering more data into collection 
management analysis. This allows patrons to become more involved and engaged with library collections through their studies. Their interlibrary loan requests are direct representations of their research needs and now, those needs are contributing to the building of pertinent collections. These studies evaluate the usage of Interlibrary Loan in terms of progressing trends and impact within libraries, or in other words, the impact on internal decisions and changes, but not their specific value to patrons or impact on library's assessment initiatives to demonstrate overall value to patrons and administration.

\section{Purpose}

This study combines the patron perception of the interlibrary loan services offered in three libraries: an ARL campus, a small private liberal arts campus, and a large state public library. The goal was to have a vehicle for gathering both satisfaction and value information for each of the services provided by a resource sharing operation in order to cross analyze patron perceptions, satisfaction, and value placed on resource sharing at each institution.

\section{Process}

A survey was created to gather the information desired, and it was designed to be completed in less than 15 minutes. (See Appendix A for the survey form). The survey wording was adjusted depending on the individual participating organization, in order to provide appropriate text for the local patrons. However, the basic content was similar for each library. The survey included an optional field where the patron could enter their name to allow follow up as desired. It also included an open question to capture anything else the previous questions did not.

Patrons identified to receive an invitation to take the survey included all patrons who had received one or more item from the services in the last fiscal year. Patrons were emailed an invitation to participate in the survey.

Responses were input into a Microsoft Access database for analysis. This allowed for drilling down in a variety of ways including by patron status and/or by department, etc.

\section{Results}

\section{Private Liberal Arts College Results}

St. John Fisher College (SJFC) received 165 survey responses from the 1100 sent out, 
resulting in a 15\% response rate. This includes a majority of faculty and doctoral student responses (See Figure 1). SJFC's survey was sent out during the summer intersession, however, and a larger response rate would be expected during an academic semester.

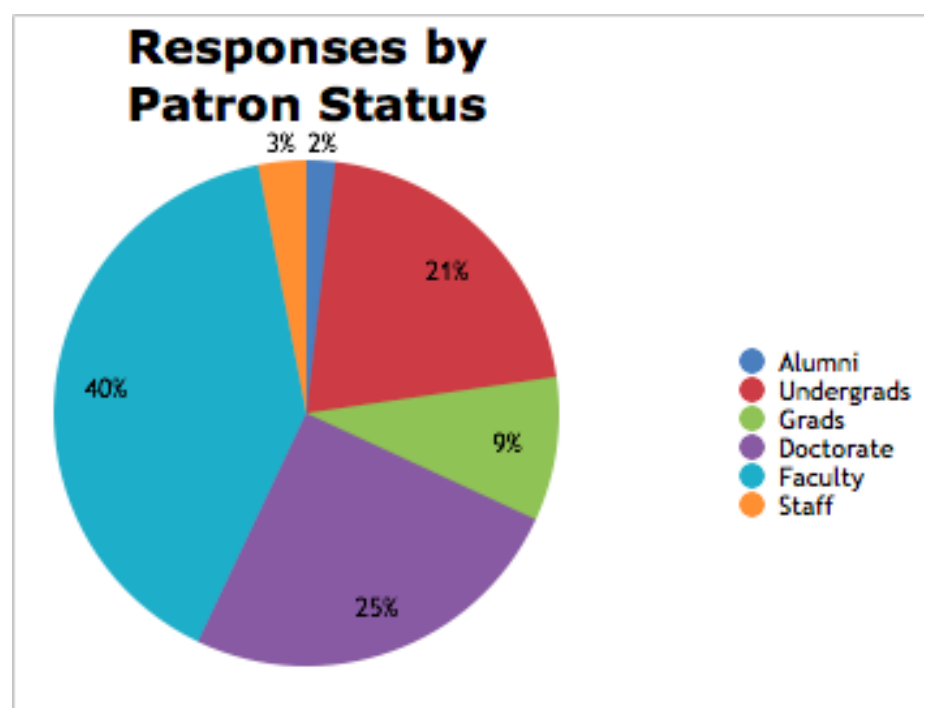

The results which address the true question of value added services came from the qualitative data examinations. The four outstanding features described in open ended comment boxes throughout the survey were a high satisfaction and high value placed on the speed of the service, quality of resources provided, ease of using the service, and the people assisting with the service. These four aspects surfaced again and again throughout the survey responses as seen below.

I have been impressed by the quality and speed of the service.

Great library. Very knowledgeable staff - always willing to meet with doctoral students. A real treasure for $S J F C$.

Love the speed! And how easy it was to just have the article sent in an email.

It's quick and easy and reliable!

The setup is really easy. I had no prior knowledge of ILL but I could figure it out on my own. 
Quantitative results showed very high percentages of patron satisfaction with the provision of articles, book chapters, books, and other resources. For example, 87\% of responses were 'Very Satisfied' with their experience borrowing article or book chapters with another $10 \%$ being 'Somewhat Satisfied' with their experiences. The 2\% of Dissatisfied responses expanded upon this rating and represent those rare requests which were unable to be filled within the patron's expectations.

Experiences borrowing books were close to the results for articles/book chapters with $75 \%$ of responses being 'Very Satisfied,' $12 \%$ of responses being 'Somewhat Satisfied,' and $13 \%$ of responses indicating they had not used this aspect of interlibrary loan. No Dissatisfied responses were received for the borrowing of books questions. These percentages provided an interesting insight for SJFC related to the access of purchased materials through the resource sharing system. SJFC has integrated collection development into interlibrary loan requests in such a way as to be seamless to the patron. Patrons submit loan requests with added information (i.e. Do think the library should add this title to their collection? Yes or No). Requests are reviewed by Acquisitions and either purchased or borrowed. Patrons are notified when items arrive and receive items in the same time frame whether purchased or borrowed.

The survey results related to purchased materials revealed the process was so seamless, a large percentage of patrons did not even realize it was happening. Results such as these can be exciting to work with as they provide opportunities to reflect on the goals of the service and how well they are being met. Is it a good thing that patrons don't even realize we're buying books they're requesting through interlibrary loan? Is this an opportunity to promote a value added service already happening? Is it value added according to our patrons? Would they provide more feedback in their request forms regarding use of materials if they knew how the information was being used?

The most interesting and perhaps the most applicable results for this study's purpose were the questions asking the perceived value of the service provided and why:

"We want to better understand the value our services bring to your classroom and research needs. Please indicate the importance of our services to your work."
A) Very Important
B) Somewhat Important 


\section{C) Not Important \\ D) Other (please specify)"}

"Please briefly describe the value our services provide (e.g. importance to research, importance to teaching, etc.) (300 character limit)"

The insights gained from the answers to these questions are important in determining how to align a library service with patron expectations, for example time saved, costs of time and travel, etc.

\section{Academic Research Library Results}

University of Kansas Libraries (KU) received 627 responses (18\% response rate) to their survey, of which $65 \%$ were from faculty and doctoral students. KU's survey was sent out over the last month of the spring 2013 semester.

The services included on the KU survey combined the supply of copies obtained via interlibrary loan borrowing and scanned through local document delivery; loans received via interlibrary loan; a loan requesting service from the local collections; and loan delivery to campus faculty and staff. Results showed extremely high satisfaction with all services. The qualities most referenced in the qualitative comments included speed of the service, quality of the service, convenience and recognition by the patrons of their time saved.

The only service that received greater than a $1 \%$ "very dissatisfied" satisfaction rating was the loan delivery to campus faculty and staff service. Almost all of these "very dissatisfied" ratings were from graduate students who were not eligible for the service. So the service, as currently delivered, is highly rated by those eligible for the service. This lower rating by ineligible grad students helps to indicate the strong interest they have for this service.

As with the other libraries, the most useful information was obtained in the values section. Capturing patrons' Likert scale based ratings provided some basic numbers that can be used. It affirmed that services are overall very important. Impressive charts like Fig 2 can be used in marketing and with stakeholders. 


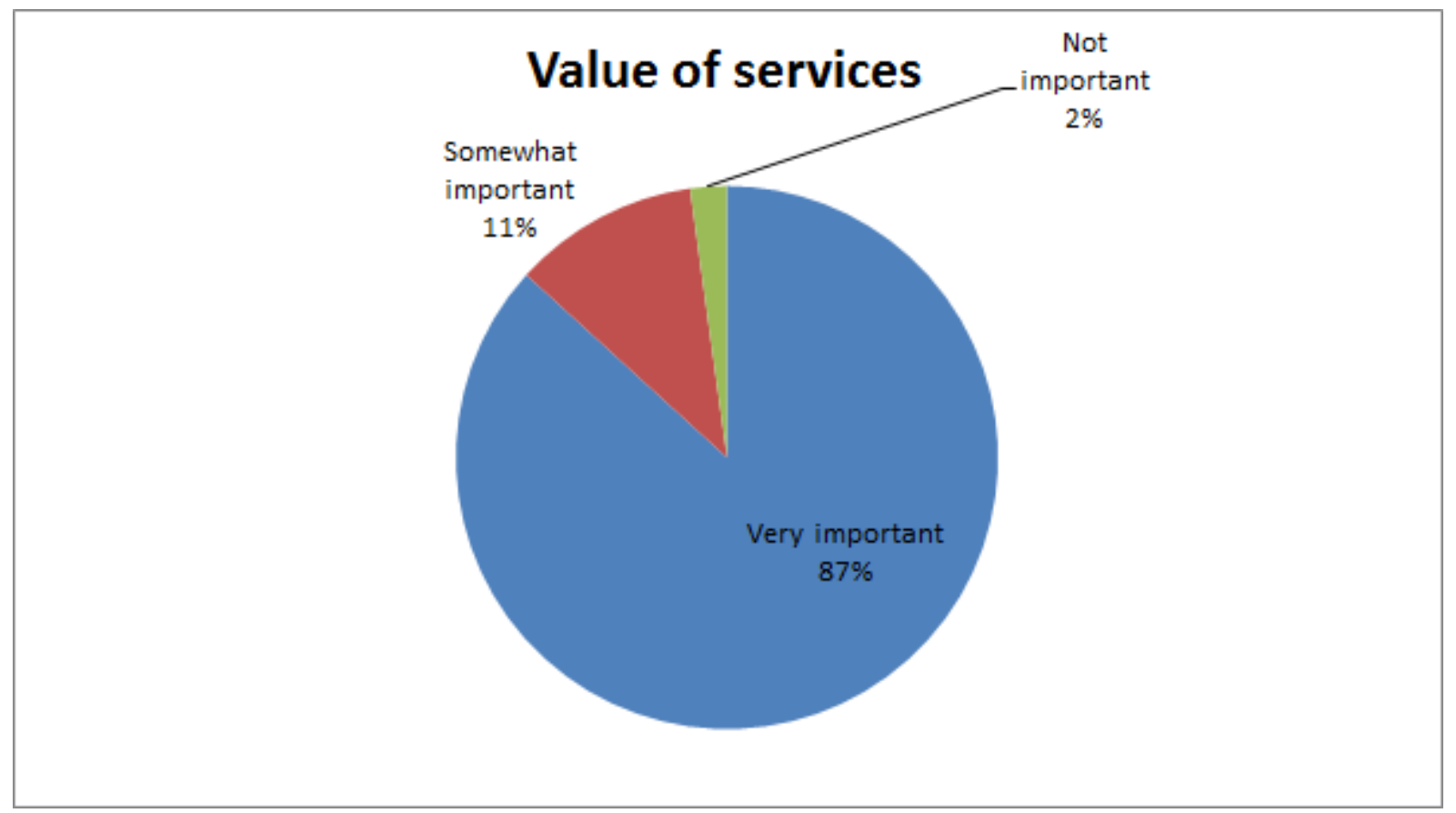

However, the most useful content came from the numerous comments provided when patrons were asked to describe the value to their research and classroom needs.

The use of either quantitative or qualitative data both come with caution. One cannot solely rely on one or the other. It is the combination of both types of data, along with common sense interpretation, that leads to the most effective decisions. A single negative qualitative comment that impacted an individual should be of concern but must be viewed in the context of all information received.

Almost all comments provided in the values section (i.e. "We want to better understand the value our services bring to your classroom and research needs. Please indicate the importance of our services to your work. A) Very Important, B) Somewhat Important, C) Not Important, D) Other" and "Please briefly describe the value our services provide (e.g. importance to research, importance to teaching, etc.") were positive to ecstatic. There was a good variety but some common themes included time savings, type of support given, and impact. Numerous answers spoke to various types of time savings with words such as "massive" that helps to demonstrate strong impact. Time is one of the most precious assets so this was helpful to see. Multiple faculty spoke to the positive impact on both their teaching and research including phrases such as “impossible to do my work" and "crucial." Survey respondents also provided specific types of assistance such as access to global information, support for grants being submitted, and 
completion of dissertations. The few comments from respondents who rated the value as "somewhat important" or "not important" noted it was more for their professional development and quality of life. See Appendix B for a sample of the 469 responses.

\section{Public Library Results}

The New York Public Library also participated in this study, receiving 550 responses (a $29 \%$ response rate) from their community. When evaluating the qualitative responses collected, the feature that stood out most was access to resources. This can be attributed to a public library's patrons' lack of affiliation with an academic institution, which was mentioned several times in the comments submitted. Patrons indicated their research work relating to a variety of

professions which required extensive resources not readily accessible through the public library's local collections. The ability to access a multitude of university collections through their public library's interlibrary loan service indicated a high value of this service to those patrons utilizing the service.

Support for these qualitative comments was complemented by the quantitative ranking of the value of NYPL's ILL Services as 78\% 'Very Important,' 19\% 'Somewhat Important,' and only $2 \%$ 'Not Important.' One difference from the academic institutions' surveys for the public library is how, analyzing and sharing their survey results internally and externally ties into the public funds supporting the public library and the services they are able to provide. Gaining further insight into how the public perceives interlibrary loan accessibility through their public library will allow the public library to not only change and improve their service based on user feedback, but also share out and market more pertinent information to their public based on the features their patrons found most valuable - that is access to extensive global collections.

\section{Comparisons}

Comparing all three organizations, the value of ILL services, according to patron perceptions, ranks overwhelmingly very important with 79\%, 93\%, and $82 \%$ for the public library, small liberal arts college, and a research university respectively. The four most important features in all three result sets were: speed, access, people, and quality. The difference in results reflects partly the differing expectations of the patrons as well as, of course, the different level of service provided that is described by these features. So while satisfaction rates were high across 
all three surveys, academic institutions are focused on information literate scholars and holistic learning experiences; their assessment and value added services align with goals of the institution as well as their libraries. Their patrons are attending their institutions for particular purposes and therefore the survey results will be slightly different than the public library survey.

The large public library generated more varied responses, providing insight into where patrons place value on the services offered. Public institutions align their services to more outward facing goals than academic institutions. For example, patrons are more concerned with the funding being provided to the services offered by a public institution. Understanding more about what patrons consider satisfactory and valuable in regard to their usage of the library's services is important to ensure those services continue to meet needs with high quality.

Patrons, however, continue to be focused on accessing resources, quickly, easily, and with knowledgeable staff available to assist them through the whole process. These are the key values patrons shared throughout their participation in this study.

\section{Next Steps}

The information gathered during this study was utilized for more than affirmation of a job well done. Each participant used their patrons' data to tweak benchmarks and workflows within their department, as well as market services less known to their communities. Patron confusion and dissatisfactions were also identified and targeted for improvement. Many respondents in the University of Kansas survey commented that they didn't know a specific service existed. In response, the University added a step so that when a new patron uses one of their services for the first time they are sent an email with information on additional services available. At St. John Fisher, where confusion regarding Document Delivery services was evident, the decision to continue incorporating this service as a seamless aspect of interlibrary loan, rather than marketing it as a separate service, allowed further improvements in workflow to take place.

Information was shared within the library to assist in a broader understanding of patron wants and needs. Identified features of importance combined with individual quotes were used for marketing and outreach within the library. Note of those patrons who did not currently utilize the ILL service was also made as a target audience to explore further. This method of gathering patrons' value of services provided is also a model for consideration for other library services.

Most importantly, the information was tied into ongoing assessment initiatives to support 
goals and student learning. As ILL departments continue to collect information and interact with their patrons, they will be able to utilize their information to contribute to library wide assessment initiatives, which in turn support larger organization initiatives.

Next steps for libraries and resource sharing practitioners to consider include

i. Assessing the potential for cost savings for the library through buy vs. borrow practices and subscriptions.

ii. Continuing to explore time saved, cost savings and other aspects of value noted by patrons. This will allow libraries to focus on where they are making an impact on their patrons' experience and success.

iii. Focusing on patrons who do not use the resource sharing service and identifying potential weaknesses. Are there differences between students who don't use services and students who do, for example grades attained? Would the values placed by current customers not be seen by the patrons who do not use the services?

iv. Using the collected data to ask better questions and revise appropriate services as well as placing the collected data against a larger framework to identify gaps and further needs.

\section{Conclusion}

As Oakleaf describes in multiple ways and with multiple examples, a main focus of assessment efforts and contributions should be on "where we are helping in areas of institutional relevance and strategic directions," as well as "mobilizing library administrators."

Assessment consists of compiling data to help tell a story. Each organization has a different story to tell. Resource sharing is one piece of the puzzle that puts the story together. Providing information to other "pieces" of the puzzle will assist in telling a more vibrant and detailed story. Understanding the values placed on services by the patrons will in turn help provide the narrative that can best be understood by patrons and stakeholders. This is the tale stakeholders will recognize as valuable in which to invest their time, money, energies, and expectations. 


\section{Works Cited}

Brown, Jeanne. "Developing a Library Value Indicator for a Disciplinary Population." Library Assessment Conference: Building Effective, Sustainable, Practical Assessment. Baltimore, MD: Association of Research Libraries, 2010.

Harless, David and Frank Allen. "Using the Contingent Valuation Method to Measure Patron Benefits of Reference Desk Service in an Academic Library." College and Research Libraries (1999): 56-69.

Mak, Collette. "Resource Sharing among ARL libraries in the US: 35 years of growth." Interlending and Document Supply (2011): 26-31.

Massie, Dennis. "Interlending trending: a look ahead from atop the data pile." Interlending and Document Supply (2012): 125-130.

Oakleaf, Megan. The Value of Academic Libraries: A Comprehensive Research Review and Report. Chicago, IL: Association of College and Research Libraries, 2010.

Schulenberger, David. "The Relationship between University Assessment and Library Assessment." Library Assessment Conference: Building Effective, Sustainable, Practical Assessment. Baltimore, MD: Association of Research Libraries, 2010. 


\section{Figures}

Figure 1Responses by patron status at St John Fisher College

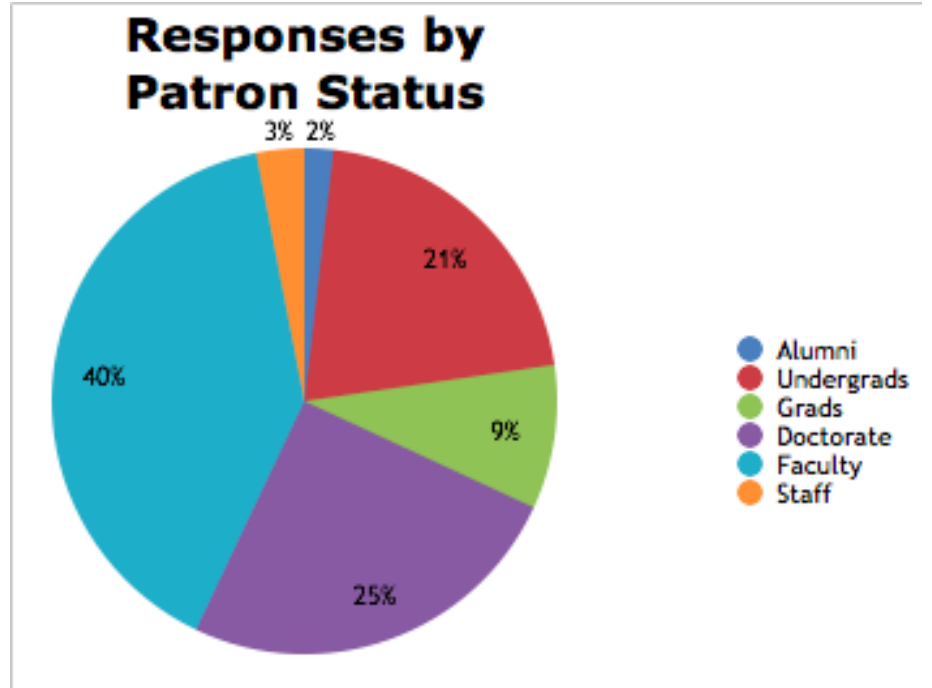

Figure 2 Value of services to patrons at the University of Kansas

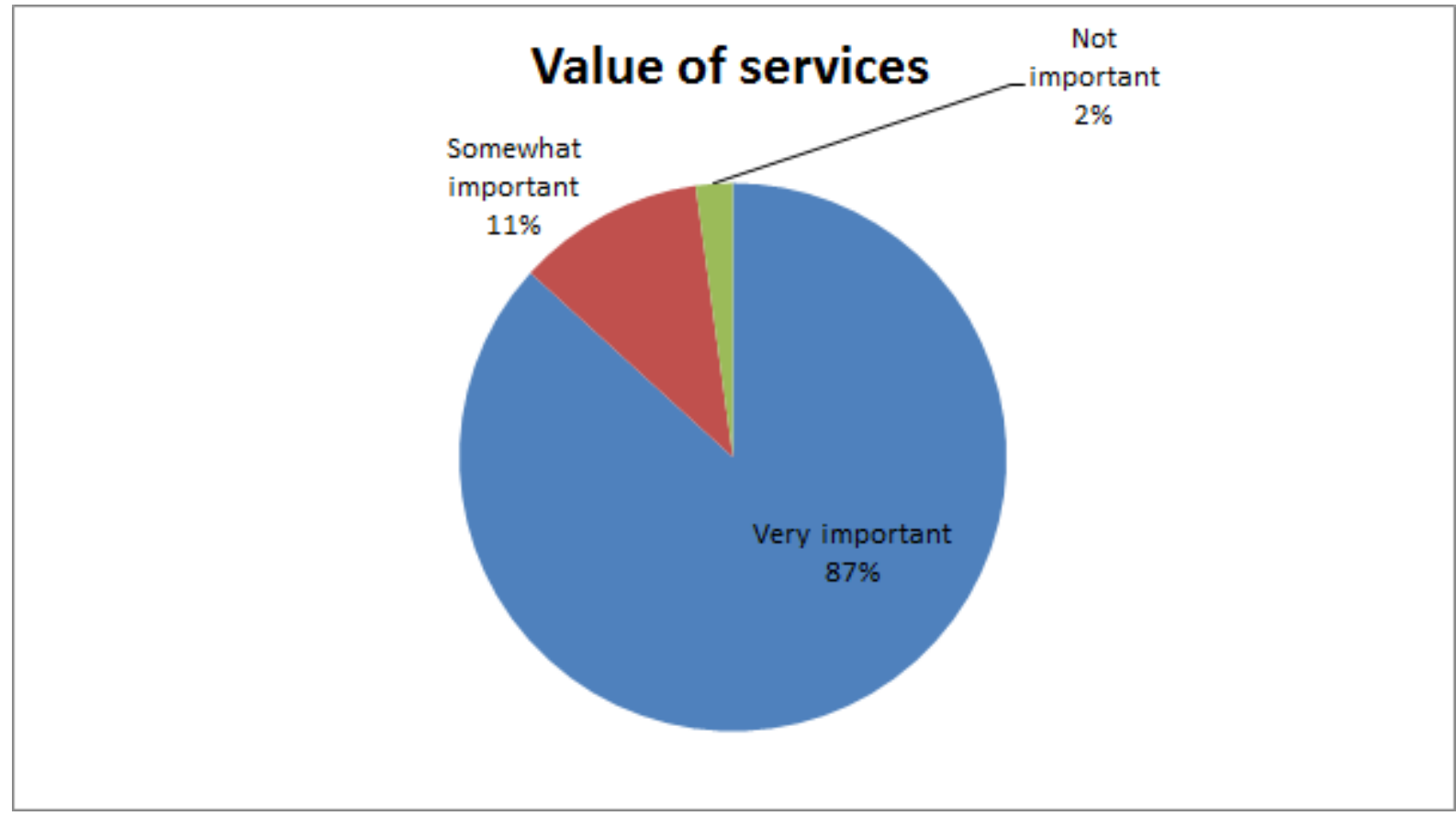




\section{Appendix A}

Capture Method: SurveyMonkey

Questions tweaked depending on services provided.

Example of message: The purpose of this short survey is to capture a broad understanding of our current patrons' satisfaction with our resource sharing services and to begin to understand the value they place on our services. The survey data will be used to evaluate our current practices and policies. We do not collect any individual identifying information. Questions to Lars Leon (lleon@ku.edu or 785-864-3073)

Survey Page 1

1. Your affiliation

Faculty, Unclassified professional staff, University support staff, Master's student, $\mathrm{PhD}$ student, Postdoctoral research, Undergraduate student, Affiliate, Other (please specify)

2. Your Department

List of all departments included + Other (please specify)

$\underline{\text { Survey Page } 2}$

Providing copies of articles and/or book chapters to you (requested through Web Retrieve) This is our service where we either make copies of articles or book chapters from the KU Libraries collections for you and/or obtain them for you from other libraries and suppliers.

3. How satisfied were you with this service over the past 9 months?

Very satisfied / Somewhat satisfied / Somewhat dissatisfied / Very dissatisfied / Haven't Used

4. Why? (E.g. speed, quality, etc.)

Survey Page 3

Providing materials to you Not Available in KU Libraries (requested through Web Retrieve)

This is our service where we borrow books, DVDs, etc. from other libraries via Interlibrary Loan for you...

5. How satisfied were you with this service over the past 9 months?

Very satisfied / Somewhat satisfied / Somewhat dissatisfied / Very dissatisfied / Haven't Used

6. Why? (E.g. speed, quality, etc.) 


\section{Survey Page 4}

\section{Materials pulled from KU Libraries' shelves by our staff and picked up by you at our}

service desks

This is our service where you request via our Library Catalog using Retrieve from Shelf and we pull the materials from our shelves and place them at one of our service desks for you to pick up.

7. How satisfied were you with this service over the past 9 months?

Very satisfied / Somewhat satisfied / Somewhat dissatisfied / Very dissatisfied / Haven’t Used

8. Why? (E.g. speed, quality, etc.)

\section{Survey Page 5}

\section{Loans delivered to faculty/staff Lawrence campus office}

This is our service where Lawrence campus faculty/staff can request to have materials delivered to their department (wherever Campus Mail delivers)...

9. How satisfied were you with this service over the past 9 months?

Very satisfied / Somewhat satisfied / Somewhat dissatisfied / Very dissatisfied / Haven't Used

10. Why? (E.g. speed, quality, etc.)

Survey Page 6

11. We want to better understand the value our services bring to your classroom and research needs. Please indicate the importance of our services to your work:

Very important / Somewhat important/ Not important/ Other (please specify)

12. Please briefly describe the value our services provide (e.g. importance to research, importance to teaching, etc.) (300 character limit)

13. Is there anything else you would like to tell us about our resource sharing services? (300 character limit)

14. If you are willing to be contacted please enter your name and best contact information. (This is optional).

End of survey. 


\section{Appendix B}

Selected additional qualitative comments in response to values question (Academic Research Library)

$\mathrm{PhD}$ student on receiving copies

This has saved me a massive amount of time as I no longer have to leave my work to go to search through the stacks for a single article. It is an exceptional service that helps me immensely.

$\mathrm{PhD}$ student in Social Welfare

I have used your service for both teaching and research, primarily in relation to ordering articles/books not available through the KU library. It would be impossible to do my work without it!

Faculty, Pharmacy

This is crucial to my research as I rely heavily on articles from the 90's and 80's that are not available electronically.

Faculty, Ecology and Evolutionary Biology

Most of the time that I order something I am working on a grant with a deadline. The speed is essential for progressing on my grant.

Faculty, Ecology and Evolutionary Biology

Research: Through the library, I am able to access libraries all over the country, even libraries overseas. I can't imagine how I would manage without your services.

Master's student, English

Immense help in terms of time management and productivity - I'm able to request materials at the drop of a hat instead of waiting to be on campus to get them myself.

PhD student, BioEngineering

There is no way I could do any literature review or write the background of my dissertation without WebRetrieve. This is a must have service.

Faculty, Molecular Biosciences

Getting articles and books not available at KU libraries makes a big difference in research and teaching--this service provides materials to increase the scholarly content in both areas.

PhD student, Medicinal Chemistry

Virtually essential to research ( 1/4 of papers I need to carry out normal research come from these services) 
Postdoctoral research, Pharmaceutical Chemistry

While the KU journal collection is large, there are occasionally older documents or articles that are relevant but are published in more obscure journals. These are often important to research.

The library is the backbone of research and teaching. Without high-quality resources, it's impossible to conduct high-quality research. Without strong library staff members to help students, it's impossible to help students learn the skills they need to survive in an informationsaturated world.

-Faculty, Journalism

In an age when some believe that the book is dead, I think the services KU Libraries provide (not to mention the books themselves), make it easier to access and reminds us how indispensable the physical book remains.

-Faculty, Architecture

Web-Retrieve, ILL, and Trip-Savr are essential to the success of my research program. They are convenient and efficient, and they greatly facilitate my research.

-Faculty, English

I'm researching but off campus. The web retrieve is essential. It saves me 4 hour at least a week. Thank you!

$-\mathrm{PhD}$ student

Without your service my research can't be done

-PhD student, History

For instance, when I'm searching for an article that we don't have and isn't reproduced in an edited volume, I always turn to interlibrary loan and can be assured that I'll have the article for use in my class within about a week's time. I often have students tell me that they have used this service to locate hard-to-find materials for my classes (Japanese film) and this has resulted in better papers and ultimately better classes.

-Faculty, Film and Media Studies 